\title{
EXPERIMEN'TAL OBSERVATIONS ON THE COAGULATION OF OXALATED PLASMA, WITH A STUDY OF SOME CASES OF PURPURA *
}

\author{
J. HAROLD AUSTIN, M.D., ANd O. H. PERRY PEPPER, M.D. \\ PHILADELPHIA
}

Stimulated by Whipple's ${ }^{1}$ study of the blood-plasma of purpura, and also by the availability of a few patients with purpuric manifestations, we undertook the study, from the point of view of clinical adaptability, of the methods of determining the coagulation properties of the bloodplasma of purpura. We found it necessary, however, in connection with this work, to study in detail the general principles of coagulation, and we therefore present our results under the two general heads of (1) "Experimental" and (2) "Clinical Studies."

\section{EXPERIMENTAL STUDIES}

In the course of our early work we were impressed with the ease of preparing from dog's blood-cells a solution with great thromboplastic activity and comparatively so free from prothrombin or thrombin as to be available as a source of thromboplastin in clinical studies. This solution was prepared as follows: From a normal dog that had fasted twenty-four hours, blood from the jugular vein was allowed to flow into a 1 per cent. sodium oxalate solution in the proportion of nine parts of the former to one of the latter, which was immediately centrifugalized. The clear plasma was drawn off and preserved; the cells were washed three times with 0.85 per cent. sodium chlorid solution and then diluted with three volumes of distilled water. When hemolysis had occurred, 0.85 gram of sodium chlorid was added for each 100 c.c. of distilled water. This is quite similar to the solution of platelets prepared by Bayne-Jones; we have not, however, for our purposes found any advantage in isolating the platelets in pure form.

To determine whether this solution contained any considerable amount of thrombin or available prothrombin it was mixed with a solu-

\footnotetext{
*Aided by a grant from the Committee on Scientific Investigation of the American Medical Association.

*From the medical wards of the University Hospital and the John Herr Musser Department of Research Medicine, University of Pennsylvania.

*Submitted for publication in The ARChives Jan, 21, 1913.

1. Whipple, G. H.: Hemorrhagic Disease. The ARchives Ivt. Med., 1912, ix, 365 .
} 
tion of pure fibrinogen prepared according to Howell's ${ }^{2}$ method, except that dog's plasma was used instead of cat's plasma, as follows: 0.5 c.c. fibrinogen solution +0.5 c.c. blood-cell solution +0.3 c.c. $\mathrm{CaCl}_{2}$ solution ( 2 per cent.). No clotting occurred in an hour, thus proving this solution to be free from thrombin or uncombined prothrombin.

T'o determine coagulation time the mixture to be tested was placed in a small test-tube and mixed by shaking. Once every half minute, from the time the calcium was added, a platinum loop was dipped into the mixture and the beginning of coagulation was arbitrarily fixed as the time when first a strand of fibrin could be drawn out of the fluid by the platinum loop. The platinum loop was then laid aside and once a minute the test-tube was tilted until it could be turned upside down without change of position of the clot; the time when this was possible was taken as the time of complete coagulation. This was the routine procedure in all experiments.

To determine whether the blood-cell solution contained any fibrinogen it was tested with a solution containing thrombin, obtained as follows: To 1 c.c. of dog's oxalated plasma was added 0.3 c.c. of calcium solution. When clotting was entirely completed the clot was removed and the fluid pressed from it. The resulting clear serum remained free from clot for an hour, but when added to fibrinogen solution clotting occurred. This serum was added with calcium to the blood-cell solution, as follows: 0.5 c.c. blood-cell sclution +0.5 c.c. serum +0.3 c.c. calcium solution. No clotting occurred in an hour, proving the blood-cell solution to be free from fibrinogen.

That this solution shows the properties of Howell's thromboplastin is clearly demonstrated in the accompanying experiment (Table 1) with dog's oxalated plasma $\left(D_{2}\right)$, which, on standing in the ice-chest for a few days, had lost some of its original activity.

Table I.-Experiment Demonstrating Action Upox Dog's Plasma

\begin{tabular}{|c|c|c|c|c|}
\hline $\begin{array}{c}\text { Plasma } \mathrm{D}_{2} \\
\text { c.c. } \\
\ldots\end{array}$ & $\begin{array}{c}\text { Blood-Cell } \\
\text { Solution, } \\
\text { c.c. }\end{array}$ & $\begin{array}{c}\text { Caleium } \\
\text { Solution, } \\
\text { c.c. }\end{array}$ & $\begin{array}{l}\text { Begins, } \\
\text { Minutes } \\
\ldots \ldots \ldots\end{array}$ & $\begin{array}{c}\text { Complete, } \\
\text { Minutes } \\
\ldots \ldots \ldots\end{array}$ \\
\hline 0.5 & & 0.15 & 7 & 15 \\
\hline 0.375 & 0.125 & 0.15 & $1 \%$ & 3 \\
\hline 0.25 & 0.25 & 0.15 & $1 / 3$ & 2 \\
\hline 0.125 & 0.375 & 0.15 & 1 & $11 / 2$ \\
\hline & 0.5 & 0.15 & * & $\ldots$ \\
\hline
\end{tabular}

* None in 1 hour.

Further experiments with this blood-cell solution follow:

On removing the clot that had formed after adding calcium to plasma $\mathrm{D}_{2}$, a serum was left which would not cause the clotting of a

2. Howell, W. H.: The Preparation and Properties of Thrombin, Together with Observations on Antithrombin and Prothrombin. Am. Jour. Physiol., 1910, xxvi, 453. 
solution of fibrinogen. On the subsequent addition, however, of the blood-cell solution clotting was prompt; for example:

0.5 c.c. fibrinogen solution +0.5 c.c. serum $\mathrm{D}_{2}+0.3$ c.c. calcium; no clotting in seventeen minutes.

On adding 0.5 c.c. blood-cell solution: Clotting begins, three minutes; complete, four and one-half minutes.

This experiment was repeated with a slight variation as follows:

0.5 c.c. fibrinogen solution +0.5 c.c. blood-cell solution +0.3 c.e. calcium; no clotting in eighteen minutes.

On adding 0.5 c.c. serum $D_{2}$ clotting begins, two minutes; complete, four minutes.

A slightly different result was obtained when the blood-cell solution and serum $\mathrm{D}_{2}$ and calcium were allowed to stand together with the subsequent addition of fibrinogen solution; thus:

0.5 c.c. blood-cell solution +0.5 c.c. serum $\mathrm{D}_{2}+0.3$ c.c. calcium.

No clotting in fourteen minutes. On then adding 0.5 c.c. fibrinogen solution a small distinct clot formed after 18 minutes, but never clotted solidly.

It is evident that clotting occurred only when all four solutions were combined, the fibrinogen, the serum, the blood-cell solution and calcium; no three of these sufficed to produce coagulation.

The explanation which we offer for these experiments is based on Howell's theory. On standing in the cold the prothrombin of plasma $\mathrm{D}_{2}$ was to a considerable extent bound by antithrombin, causing a delayed clotting time. On the addition of blood-cell solution, however, the prothrombin-antithrombin combination was broken up and prothrombin rendered available. In the serum left after clotting plasma $\mathrm{D}_{2}$, all the prothrombin is apparently combined with antithrombin and is inactive until set free by the addition of the blood-cell solution.

With a view to determining the source of this thromboplastin in the blood-cell solution, the blood-cells of oxalated plasma were centrifuged. White blood-cells from the upper layer were collected and after repeated washing treated with three volumes of distilled water. Erythrocytes from the bottom of the centrifuge tube were collected separately, and after washing, were hemolyzed in three volumes of distilled water. The remaining cells of the middle layer were then mixed and similarly washed and hemolyzed. These three solutions so obtained were then tested in ascending dilutions for their power of accelerating the coagulation of a dog's oxalated plasma. This power was found to disappear in each of the three solutions at approximately the same dilution. The thromboplastin was not, therefore, derived exclusively from the leukocytes, nor erythrocytes, but can be obtained, as also shown by Howell ${ }^{3}$ and by

3. Howell, W. H.: The Nature and Action of the Thromboplastic Substance of the Tissues. Am. Jour. Physiol., 1912, xxxi, 1. 
Bayne-Jones, ${ }^{4}$ from any of the blood-cells, but particularly from the blood-platelets.

For our purpose, the study of clinical cases, this solution of thromboplastin is to be preferred to the commonly-used tissue extracts, because of its greater ease of preparation and its greater activity.

To determine whether the destruction of prothrombin or its fixation by antithrombin could be hastened by exposure of the dog's oxalated plasma to heat, the plasma was kept at $47 \mathrm{C}$. for half an hour. This usually retarded coagulation (see Table 2 ), but the effect varied in differ- ent plasmas.

Table 2,-Retardation of Coagulation by Subjecting Dog's Oxalated Plasma to Heat

\begin{tabular}{|c|c|c|c|}
\hline \multirow[b]{2}{*}{ Plasma $\mathrm{D}_{3}$, c.c. } & \multirow[b]{2}{*}{$\mathrm{CaCl}_{2}$, c.c. } & \multicolumn{2}{|c|}{$\ldots$ Clotting ___ _ _ _ _ } \\
\hline & & Begins, Minutes & Complete, Minutes \\
\hline 1 & 0.3 & 3 & 5 \\
\hline$I^{*}$ & 0.3 & 4 & 6 \\
\hline $1 \dagger$ & 0.3 & 9 & 18 \\
\hline
\end{tabular}

* After heating to $47 \mathrm{C}$. for 15 minutes.

i After heating to $47 \mathrm{C}$. for 30 minutes.

If, however, such a heated plasma was allowed to stand at roomtemperature for twenty-four hours, clotting either did not occur on the addition of calcium solution, or was very much delayed (see Table 3 [3]). The thromboplastin solution, however, still exerted a markedly accelerating effect on the coagulation of such heated plasma (see Table 3 [4]) and restored the coagulation time to a point close to that found before heating (see Table $3[1$ and 2$]$ ).

Table 3.-Retardation of Clottixg of Heated Plasma After Standisg for TWENTY-Focr Hours

\begin{tabular}{|c|c|c|c|c|}
\hline \multirow[b]{2}{*}{$\begin{array}{c}\text { Plasma } D_{\tilde{n}} \text {, } \\
\text { c.c. }\end{array}$} & \multirow[b]{2}{*}{$\begin{array}{l}\mathrm{CaCl}_{2}, \\
\text { e.e. }\end{array}$} & \multirow[b]{2}{*}{$\begin{array}{l}\text { Thromboplastin } \\
\text { Solution, c.c. }\end{array}$} & \multicolumn{2}{|c|}{ _.. Clotting _____ } \\
\hline & & & $\begin{array}{l}\text { Begins, } \\
\text { Minutes }\end{array}$ & $\begin{array}{l}\text { Complete, } \\
\text { Minutes }\end{array}$ \\
\hline $\begin{array}{l}1 \\
0.75\end{array}$ & 0.3 & 025 & $\begin{array}{l}2 \\
11 / 2\end{array}$ & $\begin{array}{l}41 / 2 \\
2\end{array}$ \\
\hline$\ldots \ldots \ldots 1^{*}$ & 0.3 & & $i^{2}$ & $\ldots$ \\
\hline$\ldots \ldots \ldots 0.75^{*}$ & 0.3 & 0.25 & $21 / 2$ & 3 \\
\hline
\end{tabular}

* Plasma $D_{5}$ heated at $47 \mathrm{C}$. for one hour and kept at room temperature 24 hours. †No clot in 30 minutes.

The addition of one drop of thromboplastin to Tube 3 after it had stood for thirty minutes with no clotting, caused clotting to commence in two and one-half minutes; complete clotting occurred in five minutes. It would appear that the higher the temperature at which the oxalated plasma is allowed to stand, up to $58 \mathrm{C}$., the more rapid and the more

4. Bayne-Jones, S.: The Presence of Prothrombin and Thromboplastin in the Blood Platelets. Am. Jour. Physiol., 1912, xxx, 74. 
complete is the disappearance or fixation of its available prothrombin. An abundance of prothrombin is, however, rendered available again on addition of a thromboplastin solution. In this connection it is of interest to note that Blaizot ${ }^{\bar{x}}$ has shown that an antithrombin develops in dog's oxalated plasma on standing in the cold.

\section{INFLUENCE OF HEMOGLOBIN IN THE PIASMA ON THE ESTIMATION OF} FIBRINOGEN

The observation that when the thromboplastin solution is heated to 58 to $60 \mathrm{C}$., a marked precipitation occurs, called attention to a possible occasional source of error in the estimation of fibrinogen by Whipple's method. ${ }^{1}$ The following experiment in which a blood-cell solution and oxalated plasma have each been treated as in Whipple's method illustrates this:

Five c.c. of the thromboplastin solution were placed in a graduated centrifuge tube. A like quantity of a dog's clear oxalated plasma was placed in a similar tube. Both tubes were kept in a water-bath at 58 to $60 \mathrm{C}$. for fifteen minutes and then centrifuged for twenty-five minutes. In the tube containing the plasma was found a sediment of 0.2 c.c. of coagulated fibrinogen; in the tube containing the hemolyzed blood-cells, a sediment of 1.8 c.e. We have already seen that the blood-cell solution is quite free from fibrinogen (see above). It is evident, therefore, that proteins other than fibrinogen, which are coagulated at 58 to $60 \mathrm{C}$., are liberated from the blood cells on laking. The estimation of fibrinogen by heating to this temperature, therefore, becomes inaccurate if the plasma shows the least evidence of being tinged with hemoglobin.

\section{CLINICAL STUDIES}

In the clinical study of coagulation we believe that advantage can be taken of the thromboplastin solution described above for demonstrating the presence of prothrombin combined with antithrombin, and that this is an excellent method for detecting an increase in the antithrombin of the blood.

For the clinical study of coagulation we would, therefore, suggest the following steps in addition to a complete blood count and a careful enumeration of the blood-platelets : ${ }^{\circ}$

1. Estimation of the coagulation time of a drop of blood from the finger with one of the clinical coagulometers.

2. Take 20 c.c. of blood from a vein of the arm and mix with 2 c.c. of 1 per cent. sodium oxalate solution and centrifugalize.

5. Blaizot, L: Extractions de substances anticoagulants du plasma normal de chien. Compt. rend Soc. de Biol., 1911, lxx. 560.

6. Duke, W. W.: The Pathogenesis of Purpura Hemorrhagica with Especial Reference to the Part Played by the Blood-Platelets. The Archives Int. Med., $1912, x, 445$. 
(a) To 1 c.c. of plasma so obtained add 0.3 c.c. of a 2 per cent. calcium chlorid solution and determine beginning and complete clotting. If delayed,

(b) To 0.75 c.c. of the original plasma add 0.25 c.e. of blood-cell solution prepared as described, and 0.3 c.c. of 2 per cent. calcium chlorid, and determine beginning and complete clotting. If delayed,

(c) To 0.5 c.c. of plasma add 0.5 c.e. pure fibrinogen solution and 0.3 c.c. of 2 per cent. calcium chlorid solution and determine beginning and complete clotting.

A delay in (1) but not in (2-a) suggests that there is not sufficient calcium available in the blood for normal coagulation, but that the other constituents are normal; a delay in (2-a) but not in (2-b) suggests that much of the prothrombin present is bound by antithrombin and is therefore inactive. A poor coagulation in (1), (2-a) and (2-b) but good in (2-c) suggests that there is a deficiency of fibrinogen which can be further confirmed at (3) (see below).

A delay in (1), (2-a), (2-b) and (2-c) suggests a deficiency of prothrombin, bound or unbound, with or without a deficiency of fibrinogen.

3. Precipitate fibrinogen in 10 c.c. of plasma by heating to 58 to $60 \mathrm{C}$. for 15 minutes on a water bath. Centrifugalize in a graduated tube for 25 minutes and read amount of sediment in volume per cent. This method is useless if plasma is discolored with hemoglobin (see above).

It may be noted here that a poor filmy clot may result quite as readily from a lack of thrombin as from a lack of fibrinogen in spite of statements in the literature to the contrary. We have repeatedly observed this type of clot in working with solutions of pure fibrinogen in abundance, but containing only a trace of thrombin.

This is shown by the following experiment:

Plasma $D_{2}$ was clotted in the usual manner and the serum was expressed from the clot. On the addition of fibrinogen to the serum another clot formed and serum was again expressed; this was repeated several times, the clot becoming poorer and smaller each time. An excess of calcium was constantly maintained. The addition of fibrinogen solution to the expressed serum finally resulted in merely a few threads of clot after thirty minutes, due to the exhaustion of the thrombin.

\section{CLINICAL CASES}

Of the twelve patients whom we have studied clinically, five showed purpura, one jaundice and one severe anemia; the other five were controls of various kinds. The five patients showing purpura were of various types. Our studies of three will be described in detail.

The first is a woman, aged 24, who throughout her life had been subject to subcutaneous hemorrhagic extravasations. These had not disturbed her until the previous five years, during which time the appearance of the extravasations had been preceded by pain, ustally localized to that portion of the body where the purpuric manifestations later appeared. Her general health had not been affected. She gave the interesting history that three sisters, her mother and a maternal aunt have all presented similar purpuric lesions; only the aunt, however, suffered pain at the time of the attacks. 
The examination of the patient's blood showed: Hemoglobin, 69 per cent.; red blood-cells, 4,580,000; leukocytes, 8,400. Differential count: Polymorphonuclears, 57 per cent.; small lymphocytes, 36 per cent.; large mononuclears, 2 per cent.; transitionals, 1 per cent.; eosinophils, 2 per cent.; basophils, 2 per cent. Blood platelets (preserved by formaldehyd solution) 215,300 per c.mm. Fragility of erythrocytes in hypotonic sodium chlorid solution:

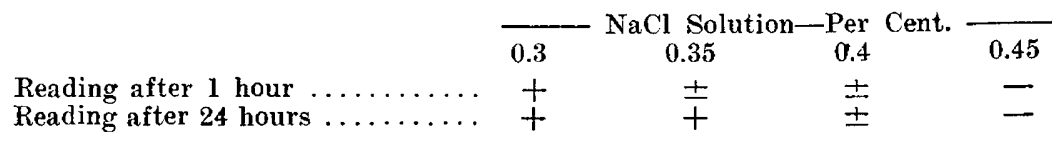

Coagulation of blood: Bogg's coagulometer, eight minutes (average of three readings). Wassermann reaction, negative (examination by Dr. John Laird).

\section{STUDY OF OXALATED PLASMA}

Coagulation time was as follows: 1 c.c. plasma + calcium 0.3 c.c.; clotting began in sixteen minutes; complete in twenty-seven minutes. The influence of thromboplastin was shown as follows: 0.75 c.c. plasma + thromboplastin solution 0.25 c.c. + calcium 0.3 c.c.; clotting began in four minutes; complete in ten and one-half minutes. Equal parts of this plasma and of normal dog's plasma clotted as promptly as the dog's plasma alone. Fibrinogen content was 3 per cent. by volume.

At a later examination, after a month's interval, similar results were obtained. The red blood-cell count was $4,520,000$; the platelets, 226,000 . Coagulation of the blood: Bogg's coagulometer, 6 minutes.

\section{STUDY OF OXALATED PLASMA ON SECOND TEST}

Coagulation time was as follows: 1 c.c. plasma + calcium 0.3 c.c.; clotting of her oxalated plasma, which delay entirely disappeared on addition of thromboplastin was as follows: 0.5 e.c. plasma +0.5 c.c. thromboplastin solution + calcium 0.3 c.c.; clotting began in four minutes; complete in nine minutes.

This patient showed, therefore, at two examinations a delay in coagulation of her oxalated plasma, which delay entirely disappeared upon addition of thrombo plastin. We are inclined to believe, therefore, that her plasma had an excess of antithrombin.

Another patient with simple purpura was a girl of 24 whose history was negative previous to two years before admission. At that time purpuric manifestations appeared and have continued to be present almost constantly since. Her symptoms consisted of hematemesis, epistaxis, bleeding from the gums, marked subcutaneous petechiae and furunculosis. A slight tendency to prolonged bleeding from cuts had been noticed. This did not begin, however, in childhood and no family history of hemophilia was obtained. Physical examination was negative except for the signs of severe anemia. Examination of the blood gave the results shown in Tables 4,5 and 6 .

Tabie 4.-Blood-Analysis in a Case of Purpura Hemorrhagica

\begin{tabular}{|c|c|c|c|c|c|c|c|c|c|c|}
\hline Date & 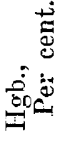 & R. B. C. & $\begin{array}{l}\dot{0} \\
\ddot{0} \\
\ddot{0}\end{array}$ & 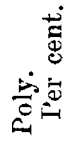 & 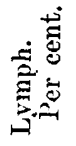 & 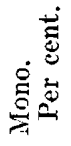 & 总离 & 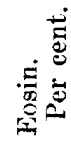 & 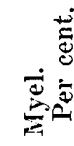 & 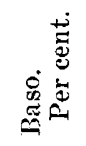 \\
\hline $5 / 31 / 12$ & 20 & $3,000,000$ & 7,680 & 74 & 20 & 5 & 1 & - & - & - \\
\hline $6 / 3 / 12$ & - & - & - & 6 & 27 & 5 & & 1 & 1 & \\
\hline $6 / 8 / 12$ & 25 & $2,500,000$ & 7,040 & 59 & 36 & 3 & 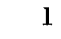 & - & - & \\
\hline $6 / 15 / 12$ & 30 & $3,160,000$ & - & - & $-\cdots$ & - & 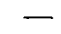 & - & - & 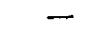 \\
\hline $7 / 8 / 12$ & 50 & $4,170,000$ & 一 & - & 一 & - & - & 一 & - & - \\
\hline $7 / 18 / 12$ & 60 & $4,240,000$ & 6,900 & - & - & - & - & 一 & 一 & - \\
\hline $7 / 24 / 12$ & 65 & $4,950,000$ & 100 & - & 一 & - & - & 一 & 一 & r \\
\hline $8 / 4 / 12$ & 75 & 4,2 & 00 & & 17 & 1 & 2 & 一 & - & \\
\hline $8 / 26 / 12$ & 6 & $3,700,000$ & 6,100 & 8 & 15 & 1 & & & & \\
\hline
\end{tabular}

Platelets-0/25/12,67,000;7/29/12, 28,500;8/30/12, 25,000. 


\section{Table 5.-Fragility of Red-Cells}

\begin{tabular}{|c|c|c|c|c|}
\hline $\begin{array}{c}\text { NaCl, } \\
\text { Per Cent. } \\
\ldots \ldots \ldots\end{array}$ & $\begin{array}{l}\text { Reading* } \\
\text { After } \\
2 \text { Hours }\end{array}$ & $\begin{array}{c}\text { Reading } \\
\text { After } \\
\text { 24 Hours }\end{array}$ & $\begin{array}{l}\text { Reading } \dagger \\
\text { After } \\
1 / 2 \text { Hour }\end{array}$ & $\begin{array}{l}\text { Reading }+ \\
\text { After } \\
24 \text { Hours }\end{array}$ \\
\hline 0.2 & 100 & 100 & 100 & 100 \\
\hline 0.3 & 100 & 100 & 100 & 100 \\
\hline 0.325 & +++ & 100 & $\ldots$ & $\ldots$ \\
\hline 0.35 & ++ & +++ & ++ & ++ \\
\hline 0.375 & ++ & ++ & tr. & tr. \\
\hline 0.4 & $+t$ & ++ & tr. & tr. \\
\hline 0.425 & + & + & & \\
\hline 0.45 & + & + & 0 & 0 \\
\hline 0.475 & tr. & tr. & . & . \\
\hline 0.5 & ft. tr. & ft. tr. & 0 & 0 \\
\hline 0.525 & o & ft. tr. & & \\
\hline 0.55 & 0 & ft. tr. & 0 & 0 \\
\hline $\begin{array}{r}0.6 \\
18 / 12 .\end{array}$ & $\begin{array}{c}0 \\
+8 / 8 / 12 .\end{array}$ & ft. tr. & . & . \\
\hline
\end{tabular}

Wassermann Reaction: Negative (Dr. Laird).

Blood-Culture: Mycobacterium Hoffmanni (Examination by Dr. Herbert Fox). Coagulation of Blood: Using the Biffi-Brooks instrument, coagulation was found to commence in six minutes and to be completed in twelve minutes.

Coagulation of oxalated plasm, as determined by a number of readings, was between four and one-half and six minutes for the beginning and nine and onehalf and twelve for the complete clotting. This is within normal limits.

This plasma, as tested on June 15, 1912, had no influence on the clotting of normal dog's plasma (see Table 6).

Tarle 6.-Effect of Plasma from Purpuric Patient on Coagulation of Dog's Plasma

\begin{tabular}{|c|c|c|c|c|}
\hline $\begin{array}{c}\text { Plasma B., } \\
\text { c.c. }\end{array}$ & $\begin{array}{c}\text { Plasma Dog, } \\
\text { c.e. }\end{array}$ & $\begin{array}{l}\mathrm{CaCl}_{2}, 2 \% \\
\text { c.c. }\end{array}$ & $\begin{array}{l}\text { Begin, } \\
\text { Minutes }\end{array}$ & $\begin{array}{l}\text { Complete, } \\
\text { Minutes }\end{array}$ \\
\hline- & 1 & 0.3 & 3 & $61 / 2$ \\
\hline 0.05 & 0.95 & 0.3 & 3 & $51 / 2$ \\
\hline 0.25 & 0.75 & 0.3 & 3 & $51 / 2$ \\
\hline 0.5 & 0.5 & 0.3 & 3 & 6 \\
\hline 0.75 & 0.25 & 0.3 & 4 & $9^{1 / 2}$ \\
\hline 0.95 & 0.05 & 0.3 & $4 \%$ & $111 / 2$ \\
\hline 1 & - & 0.3 & $41 / 1$ & $91 / 2$ \\
\hline
\end{tabular}

The fibrinogen content of the slightly hemoglobin-stained plasma was found to be a little less than 10 per cent. by volume, but this high reading was doubtless due to contamination of the plasma with products of hemolysis.

Everything is normal in this case except the severe secondary anemia and the marked reduction of platelets. We have normal coagulation, which is the usual finding in purpura, and indeed it may truly be said that the factor determining purpura is not constantly involved in coagulation as studied in oxalated plasma.

Very similar findings were shown in a patient with hemophilia, a woman aged 30, who was admitted suffering from persistent, profuse metrorrhagia with a resulting anemia. A history of hemophilia in the patient and the patient's father was obtained. This transmission of hemophilia from father to daughter, with appearance of symptoms in the daughter, while not the usual history, has been observed. The blood showed:

Aug. 10, 1912: Hgb., 37 per cent.; R. B. C., 2,140,000; W. B. C., 11,700; Poly., 87 per cent.; Lymph., 11 per cent.; Mono., 2 per cent.; Trans, -; Eosin., -.

Aug. 16, 1912 : Hgb., 38 per cent.; R. B. C., 2,430,000; W. B. C., 12,100; Poly., 79 per cent.; Lypmh., 14 per cent.; Mono., -; Trans., 6 per cent.; Eosin., I per cent.

Morphology, normal, no nucleated forms of erythrocytes. Platelets, 37,000. 


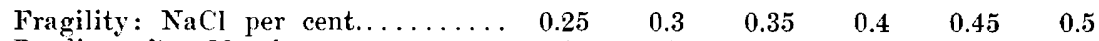
Reading after 20 min. $\ldots \ldots \ldots \ldots \ldots \ldots \ldots \ldots \ldots+ \pm \ldots \ldots$
Reading after 24 hours $\ldots \ldots \ldots \ldots+$

Coagulation of the blood measured with the Biffi-Brooks coagulometer gave beginning coagulation in eight, and complete coagulation in fifteen minutes.

Here again a normal coagulation time was seen in the presence of a reduced platelet count.

Among the cases observed was one of cholelithiasis with intense jaundice of over a month's duration. The blood-count was normal.

Hgb., 70 per cent.; R. B. C., 4,000,000; W. B. C., 5,300; differential: Poly., 64 per cent.; Jymph., 27 per cent.; Mono., 5 per cent.; Trans., 2 per cent.; Eosin., 1 per cent.; Baso., 1 per cent.

The clotting time of the blood of this case was moderately delayed as estimated with the Biffi-Brooks instrument, clotting commencing but little before ten minutes. On the other hand, the oxalated plasma, on the addition of an excess of calciuni ehlorid, clotted unusually rapidly in two and one-half minutes. Here the delayed coagulation time as measured in the whole blood was unquestionably due to the union of the calcium of the blood with bile pigments. Pure bile added to normal plasma in vitro does not delay the time of coagulation in the presence of an excess of fieshly added calcium solution, but, on the contrary, slightly accelerates it as do many foreign solutions. The following protocol is illustrative:

$\begin{array}{ccccc}\text { Plasma } \mathrm{D}_{3}, & \begin{array}{r}\text { Bile Solution, } \\ \text { c.c. }\end{array} & \begin{array}{c}\mathrm{CaCl}_{2}, 2 \% \\ \text { c.c. }\end{array} & \begin{array}{c}\text { Begin, } \\ \text { Minutes }\end{array} & \begin{array}{c}\text { Complete, } \\ \text { Minutes }\end{array} \\ 1 & - & 0.6 & 3 & 41 / 2 \\ 0.95 & 0.05 & 0.6 & 11 / 2 & 2 \\ 0.75 & 0.25 & 0.6 & 2 & 3 \\ 0.5 & 0.5 & 0.6 & 2 & 15\end{array}$

In lower dilutions no clotting occurred. If, however, the solution of bile is allowed to act for ten minutes on the calcium solution before the resulting mixture is added to the plasma, there is very distinct delay of complete coagulation and such clot as is found is poor and filmy.

\section{CONCLCSIONS}

1. A solution of hemolyzed blood-cells is the most readily prepared and active thromboplastic solution.

2. A delay in coagulation time of oxalated plasmas occurs on heating or standing. 'This is due to the formation of antithrombin, and to the union of antithrombin with prothrombin. The coagulation time in such plasmas is greatly hastened by the addition of thromboplastin solution.

3 . The presence of hemoglobin in a plasma is a source of error in the determination of fibrinogen by Whipp]e's method.

4. The scheme presented for the study of clinical cases is easily carried out and covers the essential points included in the present knowledge of this subject.

5. No method of study has as yet offered a satisfactory explanation of purpura. 